\title{
Headlines Readers' Avoidance Attitude Towards Visual Material? Effects of the Camcorder Symbol on Selective Exposure to Headlines
}

KOME - An International Journal of Pure Communication Inquiry Volume 8 Issue 2, p. 61-87. (C) The Author(s) 2020

Reprints and Permission: kome@komejournal.com Published by the Hungarian Communication Studies Association DOI: $10.17646 /$ KOME.75672.48

\section{István Kósa, Blanka Bálint, Zoltán Ambrus, Andrea Sólyom and Csilla- Dalma Zsigmond}

Department of Social Sciences, Faculty of Economics, Socio-Human Sciences and Engineering, Sapientia Hungarian University of Transylvania, ROMANIA

\begin{abstract}
Two quasi-experiments were conducted to test the effects of the camcorder symbol, a "peripheral cue" attached to headlines with either low or high utility, and the role of verbal and visual cognitive style in the process of headlines selection.

Three experimental groups were exposed to online headlines with camcorder symbol of a created portal and the control group to headlines without the camcorder $(N=250)$.

In both experiments students who preferred visual information processing chose more headlines with the camcorder. However, those with high scores on the verbal scale chose fewer headlines without the camcorder. In addition, those with high scores on both verbal and visual scales selected more and more headlines with low utility, avoiding those with the camcorder. In the second experiment $(N=160)$ in experimental group respondents' dominant cognitive style was primed with a camcorder. Primed respondents with dominant visual cognitive style chose more headlines with the camcorder than respondents in the control group. Priming decreased the selection of headlines with the camcorder among respondents high on both scales, and average scores on verbal scale and low on visual scale, confirmed by eye-tracker.
\end{abstract}

Keywords: selective exposure, Dual Coding Theory, Informational Utility Model, Elaboration Likelihood Model, eye tracking 


\section{Introduction}

Today's wide-choice and fragmented media environment has become saturated with images which serve as eye-catching cues for content selection (Zillmann, Knobloch, \& Yu, 2001). Up to now, however, most research has focused on news selection based on textual cues, neglecting the proliferating role of visuals (Fahmy, Bock, \&Wanta, 2014; Powell, van der Meer, \& Peralta, 2019). By testing three theoretical models - the Elaboration Likelihood Model, the Dual Coding Theory and the Information Utility Model -, the purpose of the current study is to take into consideration both cues in question. With this aim it uses headlines, with camcorder symbols attached to them in order to detect the factors and their inter-relationship that play a role in selective exposure. An ecologically valid news setting helped the research design to be accomplished: although news providers are aware of the power of imagery, and their intention is to enhance all news items with video made on the spot, it frequently happens that the camcorder symbol, suggesting the availability of a video footage, appears next to news with low utility or subjective importance.

\section{Selective Exposure}

The present study draws on the conceptualization of selective exposure defined by KnoblochWesterwick (2015). She partly bases her definition on the work of Sears and Freedman, considering selective exposure to be "any systematic bias in audience composition" (1967, p. 195), and completes it with the following refinement: "(...) as well as any systematic bias in selected messages that diverges from the composition of accessible message." (KnoblochWesterwick, 2015, p. 6).

Based on selective exposure paradigm formulated by Knobloch-Westerwick (2015), the current research aims to uncover some of the factors responsible for the biases, patterns in selected messages. The paradigm in question "draws on various theoretical approaches to predict selective exposure patterns and processes", instead of searching for causes and biases in the observed behavior (Knobloch-Westerwick, 2015, p. 6, see more about paradigm in book).

From this perspective the purpose of the present paper is to uncover the role of three theories in channeling selective exposure by measuring the number of selected headlines and using eye-tracking. The three theories in point are: Information Utility Model, Dual Coding Theory and Elaboration Likelihood Model.

\section{Perceived information utility effect on selective exposure}

One of the most detailed theoretical concepts of utility regarding the selection of mass media messages was described by Atkin (1973), stating that information can help individuals to adapt to and cope with environment. In this meaning, individuals may perceive that a message can be considered to carry utility and offers practical application to problem-solving needs (Johnson \& Knobloch-Westerwick, 2017). In order to develop more specific predictions of selective exposure to information, Knobloch-Westerwick and colleagues developed a more precise model of utility, the Informational Utility Model (IUM) (Knobloch, Dillman Carpentier \& Zillmann, 2003; Knobloch, Zillmann, Gibson \& Karrh, 2002; Knobloch-Westerwick, Dillman Carpentier, Blumhoff \& Nickel, 2005).

This current research is partly based on this model, which makes use of an individualized perspective of informational utility, referring only to a single person's utility at a given moment. The conceptualization of its four dimensions - magnitude, likelihood, immediacy and efficacy 
- permits measuring not only perceived threats but also the opportunities carried by the messages (Knobloch-Westerwick, 2015).

The impact of informational utility on selective exposure has been demonstrated by empirical research (Dillman Carpantier, 2008; Dillman Carpantier, Blumhoff, \& Nickel, 2005; Johnson \& Knobloch-Westerwick, 2017) summarized by Johnson and Knobloch-Westerwick by showing up the role of first three utility dimensions in forming selective exposure patterns in the following way:

"When the content of a message conveys increased importance of the topic (magnitude), increased probability of the topic affecting the message recipient (likelihood), or increased temporal presence of the topic (immediacy), there should be greater selective exposure to the message due to these intensity dimensions of informational utility." (Johnson \&KnoblochWesterwick, 2017, p. 334)

The fourth dimension, namely the perceived efficacy was added later to the model (KnoblochWesterwick, 2015). A message expressing an increased efficacy - similar to the abovementioned increased utility intensity - also attracts more clicks and gives individuals the sensation that he or she is able to prevent, handle threats or utilize opportunities.

Taking into consideration the additive effects of the first three utility dimensions (Johnson \& Knobloch-Westerwick, 2017), the impact of high efficacy carrying messages on content selection, as well as the empirical research evidence enumerated above, the first hypothesis was formulated as follows:

Hypothesis 1 (H1). The higher the perceived utility of the events suggested by news, the more frequently headlines are selected. Irrespective of the presence or absence of a camcorder symbol, the subjects in the three research groups, and in the control group, will select more headlines with high utility than headlines with low utility.

\section{Imagery, vividness and vigilance in news research}

Although there are approaches that also take into account positive stimuli (e.g., Wentura, Rothermund \& Bak, 2000), generally negative stimuli, such as danger and threats, attain more attention (Pratto \& John, 1991). This view has also been discussed within communication research first focused on news media by Shoemaker (1996), who connected the notion of vividness with news, especially with bad news. Consistent with the assumption of importance of negative stimuli, some investigations - directly linked to the current research - have made use of news illustrations. Zillmann, Gibson and Sargent (1999), for example, examined the effects of photographs in news-magazines showing that, regardless of whether the photos attached contained violence or not, consumers spent more time reading the texts that had photographs attached. However, text articles with photographs depicting threats and victimization increased to a greater extent reported reading (Zillmann, Knobloch \& Yu, 2001; Knobloch, Hastall, Zillmann \& Callison, 2003; Sargent, 2007); the effect of thumbnail images on headline selectionwas moderated by mentioning cancer or other illnesses (Kim, 2016). Layout effects were also revealed by Graber (1988), who found that formal importance cues such as larger headlines and photo illustrations promoted selective reading (KnoblochWesterwick, 2015).

These results - based on the theories linked to vividness and vigilance - could explain especially the bigger effect of negative stimuli, e.g. threatening photographs or negative news on selective exposure in comparison with positive stimuli effect. However, they cannot satisfactorily describe selective exposure, because they are based on a simpler conceptualizing 
and operationalizing of the reaction against negative and positive stimuli - in comparison to IUM. For the sake of exemplification, consider only one dimension of the more complex conceptualization of the utility dimensions like the above-mentioned efficacy dimension: it refers to individual's own capacity perception of preventing, handling a threat or utilizing an opportunity at a given moment.

\section{Paivio and Harshman' Dual Coding Theory (DCT)}

"One of the most influential theories concerning differences in the processing of pictures and words is the dual- coding theory" - state Amit, Gottlieb and Greene (2014, p. 344). Paivio and Harshmans' dual-coding theory (1983), however, focuses not only on processing/memorizing verbal and visual information, but also on acquiring information (Blazhenkova \& Kozhevnikov, 2009). DCT consider that cognition implicates the activity of verbal system responsible for dealing directly with language and of nonverbal/imagery systems important for working with nonlinguistic objects and events (Clark \& Paivio, 1991). Information collected are dual encoded, e.g. both in verbal and imagery systems. DCT assumes at the same time that many situations and tasks can be conceptualized verbally or nonverbally, i.e. visually, and there are people who prefer either verbal or visual information processing, although human thinking is a continuous interplay between these two (Paivio \& Harshman, 1983). Their preference for one of two information processing styles is called cognitive style and it is different from cognitive ability. So it may happen that someone is a habitual visualizer without efficiently solving a cognitive task based on theimaginary, and conversley, a verbalizer may not be good at resolving a linguistic task (Révész, Bernáth and Séra, 1995). According to Koć-Januchta et al. (2019, p. 1), research ,results confirm neurophysiological differences between people with different cognitive styles" (e.g. Jawed, Amin, Malik, \& Faye, 2018; Kraemer, Hamilton, Messing, DeSantis, \& Thompson-Schill, 2014).This fact has been proved by several eyetracking investigations, showing up differences in eye-movement patterns between people characterized by diverse cognitive style (e.g. Koć-Januchta et al., 2017; Höffler, Koć-Januchta, \& Leutner, 2017).

The present research focuses, on the one hand, on Childers et al. (1985) statement: in the orientation of everyday life, verbal and visual information processing style plays a role in which of them is preferred. On the other hand, it mainly focuses on the role cognitive style plays in information and news selection, and is mainly based on Plass, Chun, Mayer, and Leutners' (1998) empirical research results. In order to analyze the students' information-selection behavior they made use of the VV-BOS (Visualizer/Verbalizer Choice Behavior Observation Scale) developed by Leutner and Plass (1998). Plass, Chun, Mayer and Leutner (1998) found that students with visual cognitive style searched mainly for visual annotations, whereas those with verbal cognitive style learned from verbal annotations. Last but not least, we take into account the findings of Koć-Januchta et al.' (2017, p. 170), namely that "vizualizers spent more time inspecting pictures than verbalizers, while verbalizers spent more time inspecting texts"

Based on these findings two of the hypothesis of first quasi-experiment of the current paper were formulated as follows:

Hypothesis 2 (H2): Respondents who prefer visual information processing would choose more headlines with the camcorder symbol attached.

Hypothesis 3 (H3): Respondents who prefer verbal information processing would choose more headlines without the camcorder symbol attached. 


\section{Elaboration Likelihood Model (ELM)}

In this research, the camcorder symbol is considered as a formal cue, anticipating having a strong effect on directing the reader's attention to a certain headline due to its vividness.

As mentioned in the introduction, news providers cannot enhance all emerging news stories with videos, and the camcorder symbol, suggesting the availability of video footage, can appear next to news with low utility. Similar to findings in studies of photographs or videos included in articles leading to an over-appreciation of their topical importance (Zillmann et al., 1999; Knobloch, Hastall, Zillmann \& Callison, 2003, and for videos Rosenstiel, 2016), we attribute the same effect to the camcorder symbol. This presumption corresponds, on the one hand, to our hypothesis that the camcorder symbol, when attached to headlines with low or high utility, amplifies the subjectively perceived utility of the news content in the eyes of the readers, and hence leads to these headlines being more frequently selected. One the other hand, according to our assumption, this is due to the fact that the readers (under the effect of these "peripheral cues", used so often and deliberately in advertising), would choose the so-called "peripheral route". In the Elaboration Likelihood Model (Petty \& Priester, 1994), the "central route" is used when evaluating subjects that are well-known or emotionally close to the subject, while the "peripheral route", requiring less deliberation or attention, is used in the case of less interesting, marginal subjects - headlines with low utility $\left(1^{\text {st }}\right.$ experimental group in the current research). In the second case, a person is more likely to be influenced by certain contextual cues, outside of the central message argument, by creating pleasant (or unpleasant) associations. These cues, often referred to as "peripheral cues" (such as color, sound, sex appeal, humor, production quality), are nowadays extensively used by the advertisers to trigger simple, but pleasurable associations with the advertised product (Sundar \& Kim, 2005). Photographs and video materials can be considered such cues, as well. However, it is worth placing emphasis on the fact that the visual cue (the camcorder symbol) is used in the present research as a monosemic graphic with unambiguous and unique meaning pretested before the first quasi-eperiment that did not add any new detail in comparison to graphics and photograps attached to texts.

The choice between the two cognitive routes depends on the relevance of the topic. The more strongly a person feels about a certain topic, the more motivated they will be to use their time, energy and mental capacity to elaborate on that topic. When the motivation is low, the less consuming peripheral route is taken (Petty \& Priester, 1994).

Based on the above-mentioned arguments the following hypotheses were formulated:

Hypothesis 4 (H4). In cases where a camcorder symbol is attached to headlines with low utility, but not attached to headlines with high utility (group 1), the subjects will select more headlines with low utility due to the camcorder (peripheral cue), compared to the same headlines without the camcorder symbol (group 4).

Regarding the control group, respondents were presented the same news portal (with the same news), but no camcorder symbol.

Hypothesis (H5). Selection of headlines with high utility (group 2) bearing the camcorder symbol will be significantly more frequent than for the same category news in the control group. 
In the absence of any theory referring to specific interactions, the effective contributions of the high perceived informational utility and camcorder - a peripheral cue in the terminology of ELM - were assumed to be cumulative.

\section{Present study}

Three theoretical models are involved in the present paper with the aim of explaining the effects of visual and textual cues onselection of headlines. Two of them refer to the possible role of visual cues - the ELM and the DCT - and conceptualize them as imageries that are processed differently from the texts. More important to us, however, was that they describe differently in detail the two aspects with a role in information processing: message characteristics (ELM) and personal traits (DCT). While the latter thinks in terms of memorizing and acquiring information, the ELM underlines the capacity of visual cues to trigger attention, which determines different paths in persuasion. In order to take the advantages of both models into consideration, we involved them at the same time.

Relative to the possible interplay between textual and visal factors, we also made use of IUM. It is suggested by the authors of the paper that the camcorder symbol does not only suggest to media users the possibility of visualizing video material linked to the given headline, but also a rise of perceived subjective utility of headlinesat a given moment.

Two quasi-experiments were run. Both of them were based on the same theoretical framework described above, but differed in the following aspects from each other:

1. Experimental conditions. Three experimental groups were used in the first research design. In the second quasi-experiment - besides the control group - there was only one experimental group that, in fact, was the same as in the first quasi-experiment third condition.

2. Priming. In the second experiment we primed the experimental group respondents' dominant cognitive style with the camcorder symbol to show up its increased effect in comparison with the first experimental design.

3. Eye tracking. In order to detect differences in eye-movement patterns between people characterized by diverse cognitive style we used an eye-tracker.

4. Main variables. The main variables involved in the first quasi-experiment were selective exposure, utility (IUM), cognitive style (DCT) and the presence or absence of the camcorder symbol attached to headlines (ELM). In addition, in the second research design, some other variables were involved, namely the presence or absence in priming the camcorder, fixation number and first fixation.

\section{First quasi-experiment}

\section{Methods}

Overview 
The Hungarian-language speaking BA and MA students from a university campus $(N=239$; gender $N=159$ women, $N=80$ men; average age $=23.6$ ) read online headlines.

Our research method utilized a laboratory quasi-experiment with a control group, during which we recorded the preference for online headlines according to headlines with high utility or low utility content, and on the possibility of viewing video footage indicated by the camcorder symbol.

The first experimental group consisted of 60 students who expressed their opinions regarding the preference - for four news items out of four headlines with high utility and four headlines with low utility - with clicks that were registered by the software. We should note that in this experimental situation we attached the camcorder symbol to four headlines with low utility; two of them positive, and two negative.

In each experimental condition we used two soft news items: two headlines with almost no utility for students as distractors.

The subjects of the second experimental group $(N=59)$ had as material-stimuli 10 news items, however, in their case the camcorder symbol was attached to four headlines with high utility, two of them positive, and two negative.

The third experimental group $(N=59)$ were also presented with 10 headlines. In this condition camcorder symbols were attached to headlines as follows: one to a negative headline with high utility, one to a positive headline also with high utility, one symbol to a negative headline with low utility and, finally, to a positive one with low utility.

The composition of the fourth condition, used as a control group, was identical to the two groups presented above $(N=61)$. The respondents, after receiving the same instructions were required to choose from the set of four headlines with high and four headlines with low utility, presented in the same order but in this control situation, the camcorder symbol was not attached to any of the headlines.

\section{Pretest}

We based the conceptualization of the utility of the headlines on the four criteria from the Informational Utility Model (IUM): perceived magnitude, likelihood, immediacy and efficacy of threats or opportunities.

For instance, a positive news item with high perceived individual utility was entitled: "Increasing the chances for recently graduated students in the labour market over the next six months, in Harghita county - foreign-language competence/knowledge could be an advantage." ('county $\mathrm{X}$ ' being the county in which the respondents' university is located). The "increasing chance" referred to the high magnitude of the forthcoming event, and the high likelihood of it directly affecting students in the immediate future ("over the next six months") - the highly perceived immediacy of the event. The part of the title stating: "foreign-language competence/knowledge could be an advantage" indicated the high efficacy - the students' opportunity to control or influence their current circumstances with only an average foreignlanguage knowledge or grade.

The real headlines, collected during September 2015, were pretested on two groups of 20 respondents $(N=40)$ from a nearby town. As described above, in order to answer the requirements of the four above mentioned utility dimensions, manipulated versions of the headlines were created. Additionally, some of the names and places were changed. Recipients were required to read all of the 12 headlines and mark/estimate voluntarily and anonymously on a 7-point Likert scale (with answers ranging between very likely and not at all likely) how likely it would be that they would read each of them if they appeared on a news portal. Based on the mean and standard deviation, we ranked the level of utility of headlines (high vs. low), and chose those eight which were included in the quasi-experiment, along with the two 
headlines that served to veil the research interest and remained constant across experimental versions.

Since the literature review has not revealed exactly what the camcorder symbol generally indicates to news readers, we could not be sure of how it was perceived, i.e. whether they recognized it as a symbol that suggested the visualization of video material. However, from our pretest of the news we were able to reveal what they thought of it: everyone involved in the pretest stated that they recognized the symbol and that it represented the possibility of watching news coverage.

\section{Experimental Procedure}

The experiment took place in the university hall, with the participation of four groups of students during October 2015. We placed six tables in the hall, far apart from each other. On one of them, we put an ACER Z5WAH notebook and the certificates of voluntary participation; on the other three, we placed the questionnaires.

We asked students to participate voluntarily and anonymously in a study, the goal of which was to test a forthcoming news portal being created especially for students in an offline environment. They then received the following instruction: "On behalf of Transindex.ro we are testing a forthcoming news portal - YouthIndex.ro - dedicated to students. Please read the headlines in the news feed in a leisurely fashion, and click on the all those you would most like to read more about. There are no good or bad choices; we are only interested in your personal choice." We then called their attention to the fact that clicking on the hyperlink would not take them to a separate page. After each of them had made their news selections, they sat at one of the other three tables where they completed the anonymous questionnaire. When they had completed these tasks, we thanked them for their participation, and one of our students aiding in the research went to the laptop and signed out of the portal, logging the results and restarting the sequence for the next participant.

\section{Experimental Materials}

The research instruments consisted of a set of headlines used as stimuli, the news portal, and the subjects' data sheet. Taking into account the practice followed by different news portals, we created, with the agreement of the original regional news portal, a copy of it with minimal differences: with changed background colour, and we applied a similar camcorder symbol to the featured 10 headlines (four low utility, four high utility content and two headlines to veil the research interest). Half of every group's members were presented the headlines in forward order, the other half were presented them in reverse order.

We recorded the selection frequency for each headline with the aid of software we had developed. This software also randomized the order in which the news items were presented for each recipient.

We ran a test experiment with 25 students to check the research design in a different university campus.

\section{Paivio and Harshman' Individual Differences Questionnaire (IDQ)}

The individual differences in the verbal-visual dimension of cognitive style were measured by the Paivio and Harshman' IDQ test. 
The dependent variable was the number of clicks on the headlines with low vs. high utility. The software recorded who clicked, how many times, on which headlines and the logins and logouts from the portal. To test our hypotheses, we used the number of clicks on the headlines to measure selective exposure to headlines with low, and with high utility.

As the independent variable in our research, we used the presence of the camcorder symbol, attached to the headlines with low utility or to headlines with high utility; as quasiindependent variables we used the scores of verbal and visual scales.

\section{Results}

\section{Preliminary Analyses}

The Cronbach-alpha of the shortened form on X language of The Paivio-Harshman's Individual Differences Questionnaire (1983) was calculated for both scales. Verbal scale items yielded satisfactory .71 , and visual items .76 values.

\section{Exposure to Headlines with Low and High Utility}

H1 was supported; there was a significant difference between the averages of the headlines from all groups with low and with high utility. The Paired Sample T-Test result demonstrates that the selection prior to experiment of the 10 headlines presented in the experiment was efficient, causing a large effect size $(N=239, M=2.48, S D=.16$ in the case of headlines with high utility, and $M=1.36, S D=.96$, in the case of those with low utility, $t=12.59, d f$. $=238$, $p=.001$; Cohen's $d=.81$, see Table 1 for details). 
Table 1

Selective exposure to headlines with low and high utility

\begin{tabular}{|l|c|c|c|c|}
\hline & $\begin{array}{c}\mathbf{1}^{\text {st }} \\
\text { group: low utility } \\
\text { headlines with } \\
\text { camcorder }\end{array}$ & $\begin{array}{c}\mathbf{2}^{\text {nd }} \text { experimental } \\
\text { group: high utility } \\
\text { headlines with } \\
\text { camcorder }\end{array}$ & $\begin{array}{c}\mathbf{3}^{\text {rd }} \text { experimental } \\
\text { group: low and } \\
\text { high utility } \\
\text { headlines with } \\
\text { camcorder }\end{array}$ & $\begin{array}{c}\text { control group: } \\
\text { headlines without } \\
\text { camcorder }\end{array}$ \\
\hline $\begin{array}{l}\text { Selective exposure } \\
\text { to headlines with } \\
\text { low utility: nr. of } \\
\text { clicks }\end{array}$ & $\begin{array}{c}M=1.57 \\
S D=1.03\end{array}$ & $\begin{array}{l}M=1.22 \\
S D=.93\end{array}$ & $\begin{array}{l}M=1.48 \\
S D=.93\end{array}$ & $\begin{array}{l}M=1.18 \\
S D=.94\end{array}$ \\
\hline $\begin{array}{l}\text { Selective exposure } \\
\text { to headlines with } \\
\text { high utility: } \mathbf{n r} \text { of } \\
\text { clicks }\end{array}$ & $M=\mathbf{2 . 6 3}$ & $M=\mathbf{2 . 3 1}$ & $M=2.48$ & $M=\mathbf{2 . 4 8}$ \\
\hline
\end{tabular}

\section{Exposure to Headlines with Low and High Utility by the Visual Scores of Respondents}

Taking into account the influence of Experimental Group Number on verbal and visual IDQ scores (see Table 2), we started the analysis with two ANOVAs to see the differences between group in IDQ scores; the results assured us of efficacy of experimental manipulation: verbal scale $F(3,235)=.38, p=.76$; visual scale $F(3,235)=.01, p=.99$.

Table 2

IDQ scores in experimental groups

\begin{tabular}{|c|c|c|c|c|}
\hline & $\begin{array}{c}\mathbf{1}^{\text {st }} \text { experimental } \\
\text { group: low utility } \\
\text { headlines with } \\
\text { camcorder, high } \\
\text { utility headlines } \\
\text { without it }\end{array}$ & $\begin{array}{c}\mathbf{2}^{\text {nd }} \text { experimental } \\
\text { group: high utility } \\
\text { headlines with } \\
\text { camcorder, low } \\
\text { utility headlines } \\
\text { without it }\end{array}$ & $\begin{array}{c}\mathbf{3}^{\text {rd }} \text { experimental } \\
\text { group: low and } \\
\text { high utility } \\
\text { headlines with } \\
\text { camcorder, mixed } \\
\text { condition }\end{array}$ & $\begin{array}{c}\text { control group: } \\
\text { headlines without } \\
\text { camcorder }\end{array}$ \\
\hline $\begin{array}{c}\text { Average score on } \\
\text { verbal scale }\end{array}$ & 17.67 & 16.69 & 17.65 & 17.07 \\
\hline $\begin{array}{c}\text { Average score on } \\
\text { visual scale }\end{array}$ & 22.27 & 22.22 & 22.18 & 22.37 \\
\hline
\end{tabular}

In order to map the possible statistical relationship between the variables of interest, we ran a series of bivariate Pearson correlations involving the following variables: verbal scale, visual scale, utility preferences and gender. The test regarding the whole dataset together $(N=239)$ revealed a significant positive relationship between verbal scale and visual scale $(r=.17, p=$ .01 ), though it could be shown up only in one of the conditions taken one by one separately: in the third condition could be detected a stronger relation between them $(r=.38, p=.01)$. In the $4^{\text {th }}$ condition - without camcorders - there was an important negative correlation between the variables verbal scale and $\mathrm{nr}$. of headlines with low utility $(r=-.32, p=.05)$. The correlation between the dummy coded gender and other variables did not arise - just as in the other Hungarian sample from 1995 (Révész, Bernáth \& Séra). However, they found an interaction between verbal-visual scores and gender - this made us to think that our fault in showing up such a statistical relationship is due to improportionality in gender.

Testing the impact of weightening the gender variable with the SPSS tool - using "Weight Cases" function availabile from the Data menu - we ran a hierarchical regression with 3 steps. In each of the 3 models the partial correlations with the gender effect on the selection of 
headlines with camcorder proved to be weak, but statistically significant (for Man 1st Model: $r=.12, p=.04 ;$ 2nd Model: $r=.13, p=.04$; 3rd Model: $r=.15, p=.01$ ).

Before starting the more detailed analyses, we made two transformations on the dataset. On the one hand, becausethere are systematic differences between the man and woman proportion in the sample, we weighted the gender variable the SPSS tool "Weight Cases", availabile from the Data menu. Thus the number of participants rose from 239 to 322 (see Table $3)$.

Table 3

Descriptive statistics of gender

\begin{tabular}{|c|c|c|c|c|c|c|c|c|}
\hline & \multicolumn{4}{|c|}{ before weighting } & \multicolumn{4}{|c|}{ after weighting } \\
\hline $\begin{array}{c}\text { men, whole } \\
\text { dataset }(N)\end{array}$ & \multicolumn{4}{|c|}{83} & \multicolumn{4}{|c|}{166} \\
\hline $\begin{array}{c}\text { women, } \\
\text { whole } \\
\text { dataset }(N)\end{array}$ & \multicolumn{4}{|c|}{156} & \multicolumn{4}{|c|}{156} \\
\hline $\operatorname{men}(N)$ & $\begin{array}{c}1^{\text {st }} \\
\text { condition } \\
20\end{array}$ & $\begin{array}{c}2^{\text {nd }} \\
\text { condition } \\
20\end{array}$ & $\begin{array}{c}3^{\text {rd }} \\
\text { condition } \\
25\end{array}$ & $\begin{array}{c}4^{\text {rd }} \\
\text { condition } \\
18\end{array}$ & $\begin{array}{c}1^{\text {st }} \\
\text { condition } \\
40\end{array}$ & $\begin{array}{c}2^{\text {nd }} \\
\text { condition } \\
40\end{array}$ & $\begin{array}{c}3^{\mathrm{rd}} \\
\text { condition } \\
50\end{array}$ & $\begin{array}{c}4^{\mathrm{rd}} \\
\text { condition } \\
36\end{array}$ \\
\hline women $(N)$ & $\begin{array}{c}1^{\text {st }} \\
\text { condition } \\
40 \\
\end{array}$ & $\begin{array}{c}2^{\text {nd }} \\
\text { condition } \\
39 \\
\end{array}$ & $\begin{array}{c}3^{\text {rd }} \\
\text { condition } \\
35 \\
\end{array}$ & $\begin{array}{c}4^{\text {rd }} \\
\text { condition } \\
42 \\
\end{array}$ & $\begin{array}{c}1^{\text {st }} \\
\text { condition } \\
40 \\
\end{array}$ & $\begin{array}{c}2^{\text {nd }} \\
\text { condition } \\
39 \\
\end{array}$ & $\begin{array}{c}3^{\text {rd }} \\
\text { condition } \\
35 \\
\end{array}$ & $\begin{array}{c}4^{\mathrm{rd}} \\
\text { condition } \\
42 \\
\end{array}$ \\
\hline
\end{tabular}

Due to the big difference between men $(N=80)$ and women $(N=159)$ we weighted the proportion according to gender, thus the number of participants rose from 239 to 322.

On the other hand, because of the fact that the IDQ scales do not contain zero, in trying to make more meaningful the regression constant we mean-centered the variables involved by subtracting the sample mean from all measurements of those variables in the data (see Hayes, 2013).

Based on these results, we ran several hierarchical regression analyses with the first three experimental groups using SPSS to test our hypothesis. To test $H 2$, we included variables in the following order: in Step 1 we entered the visual score, verbal score and dummy coded gender, in Step 2 the interaction terms of the first order (visual x verbal, visual x gender, verbal $\mathrm{x}$ gender), and in Step 3 we introduced the interaction terms of the second order (visual $\mathrm{x}$ verbal $\mathrm{x}$ gender).

$H 2$ was not supported in the case of regression which was run for the hole dataset, as the result of the partial correlation between the number of headlines with camcorder and visual scores was not significant in any of the regression analyzes with 3 models - despite the fact that of the three model, the coefficients of the first two' relationship were closed to threshold of significance: $1^{\text {st }}$ model: $r=.12, p=.059 ; 2$ nd model: $r=.12, p=.053$. However, $H 2$ could be supported for the last two significant models - in Steps 2 and 3 - of regression in the case of the $2^{\text {nd }}$ condition, and at the same time there arose the effect of verbal-visual scores on the dependent variable (see Table 4).

Table 4.

Effect of verbal-visual scores on the dependent variable

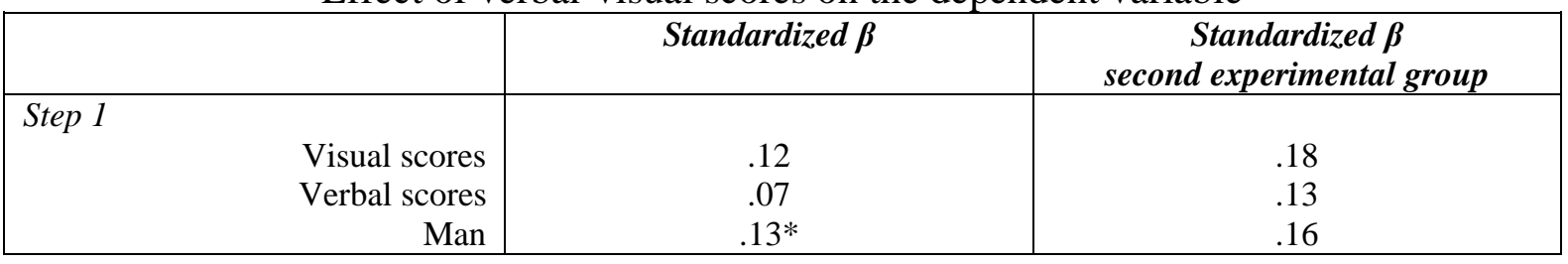




\begin{tabular}{|c|c|c|}
\hline $\begin{array}{r}\text { Model 1: } \\
F(3,240)=3.10, \\
p=.02\end{array}$ & & $\begin{array}{r}\text { Model 1: } \\
F(3,75)=2.41, \\
p=.07\end{array}$ \\
\hline \multicolumn{3}{|l|}{ Step 2} \\
\hline Visual $\mathrm{x}$ verbal scores & .09 & $.28 *$ \\
\hline Visual scores & .16 & $.40 *$ \\
\hline Verbal scores & .04 & .01 \\
\hline Verbal x Woman & -.01 & -.15 \\
\hline Man & $.13^{*}$ & .16 \\
\hline $\begin{array}{r}\text { Model 2: } \\
F(6,237)=1.87 \\
p=.08\end{array}$ & & $\begin{array}{r}\text { Model 2: } \\
F(6,72)=03, \\
p=.03\end{array}$ \\
\hline \multicolumn{3}{|l|}{ Step 3} \\
\hline Visual scores & .12 & $.36^{*}$ \\
\hline Verbal scores & .02 & -.02 \\
\hline Verbal x Woman & .03 & -.09 \\
\hline Man & $.15^{*}$ & .18 \\
\hline Verbal x man & .05 & .15 \\
\hline Visual $\mathrm{x}$ verbal $\mathrm{x}$ woman & .15 & .14 \\
\hline $\begin{array}{r}\text { Model 3: } \\
F(7,236)=2.11 \\
p=.04\end{array}$ & & $\begin{array}{r}\text { Model 3: } \\
F(7,71)=2.16 \\
p=.04\end{array}$ \\
\hline
\end{tabular}

Note for the regressionon the whole dataset. $R$ square $=.03$ for Step 1: $R$ square change $=.008$ for Step $2, R$ square $=.04$ for Step 3 .

Note for the regression on the second condition. $R$ square $=.088$ for Step 1: $R$ square change $=.077$ for Step $2, R$ square $=.011$ for Step 3

The importance of gender in selection arose in the whole dataset: in every model presenting a significant correlation with the dependent variable.

We were not able to show up a moderation/interaction between the visual and the verbal scores by classical linear regression for the whole dataset, however, by using PROCESS macro - which does not allow weighting variables - we were able to detect it. We made use of a picka-point procedure to disclose whether the groups differed, on average, from each other on the dependent variable, (determined by 5 values of the moderator variable). The selection of headlines with the camcorder symbol depends on the verbal scores beginning only from $50 \%$ (at $50 \% t=2.12, p=.03$, at $75 \% t=2.33, p=.02$, at $90 \% t=2.23, p=.02$ ).

\section{Exposure to Headlines with Low and High Utility by Verbal Scores of Respondents}

To test $H 3$, we also ran a hierarchical regression. Entering the same predictors as in the case of first hypothesis, and the number of headlines without a camcorder as dependent variable, we were not able to detect a significant relationship between the verbal scores and the latter dependent variable in the case of whole dataset $F(3,76)=2.38, p=.76$ ) for the first model, $F(6,73)=1.47, p=.19)$ for the second, and $F(7,72)=1.30, p=.26)$ for the last model. The same situation appeared when we ran the statistical test for the separate conditions.

\section{Exposure to Low Utility Headlines with Camcorder}

Deepening the analysis, we assumed $(\mathrm{H} 4)$ that in cases where a camcorder symbol is attached to headlines with low utility, but not attached to headlines with high utility (group 1), more headlines with low utility will be chosen, compared to the same headlines without the 
camcorder symbol (group 4). In order to test $H 4$, we ran an independent sample t-test between the first condition and the control condition without camcorders. As anticipated, the presence of the camcorder increased the selection of the headlines in the first condition with low utility. Participants in first condition chose more headlines with low utility $(M=1.57)$ than participants in the last one $(M=1.18)$, the attached camcorder to headlines causing a very large effect size $(d=4.69, t(118)=2.12 ; p=.03)$.

\section{Exposure to Headlines with High Utility with Camcorder}

$H 5$ should be rejected, because the camcorder high utility headlines decreased the number of clicks in the second experimental group on headlines, all with high utility $(M=2.31)$. Compared to the remaining control condition with an independent sample T-test $(M=2.48$, $(t(117)=-.84 ; p=.41)$, as well as to the mixed one $(M=2.48, p=.41)$, we can see that the lowest average value of chosen headlines with camcorder could be detected in this, in the second condition $(M=2.31)$.

We were curious whether this decrease in point can be explained by the results obtained on both scales of the IDQ test (the visual and verbal). As we aimed to keep our variables continuous, we created the independent variable involved in the following way: we sorted the scores of the variable of the verbal scores in ascending order, then, after calculating the mean, we marked both the value of one SD below the mean and of one SD above the mean. Thus, we created a new nominal variable in the next column with 3 levels, but taking into account the normal distribution of the scores in dividing it. We labeled them as follows: 1, those who had low scores on verbal scale, 2 , those who had average scores on the scale, and 3, those whose scores began from the value of $M+1 \mathrm{SD}$.

We ran an online regression in SPSS on the whole dataset, then on each group separately to test the effect of the Verbal_Scale_Group predictor on the headlines with low utility, using commands as follows: Graph $\rightarrow$ LegacyDialog $\rightarrow$ SimpleScatter $\rightarrow$ Define $\rightarrow$ Set Markers by. Results show a single significant relationship, which helps us to explain why attaching the camcorder to headlines with high utility in the second condition decreased the selection of them. We detected that those who had high scores on a verbal scale test selected more and more headlines with low utility as their visual scores increase. This means that around $17 \%$ of the respondents of the second condition, i.e. 13-14 persons, chose significantly less headlines with high utility. Statistical relationship is almost strong, and is about to reach the low threshold of its interval: $r=.4989$, see Figure 1 . 
Figure 1

Avoidance attitude towards camcorder of high score respondents' on both verbal and visual scale (see brown line). Analysis performed with SPSS Version 22.

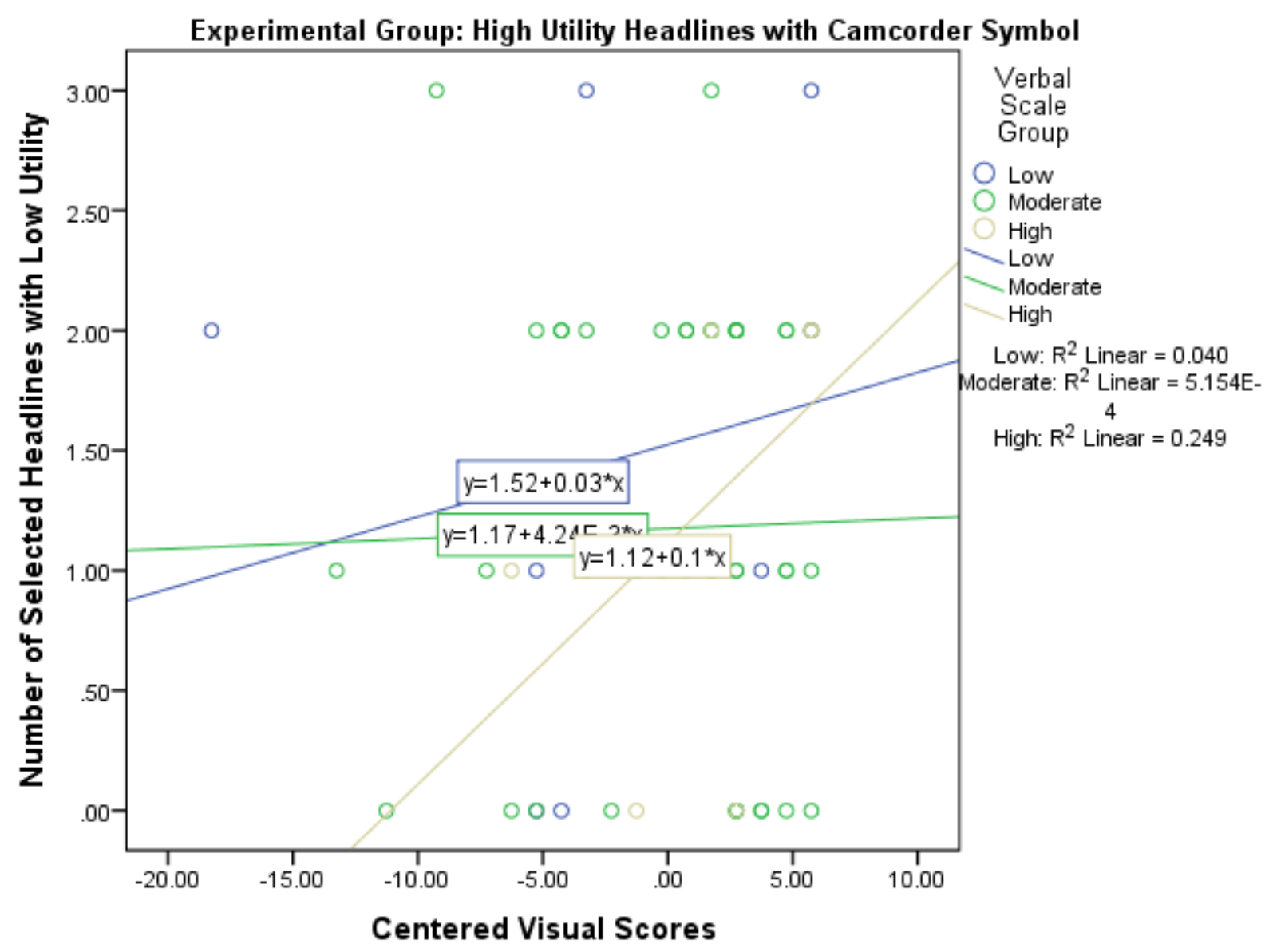

Cases weighted by Sex

\section{Discussion for Experiment 1}

This study aims to explore how textual cues with high and low utility (IUM), imagery cues (ELM) attached to news items, information processing style (DCT) and their interplay contribute to selective exposure. Although the impact of imagery on textual cues has been researched, and shown up especially the major role the photographs played in news selection (see Rosentiel, 2016), one novelty of the present study is that it tests the imagery effect in the theoretical framework of IUM. Using the conceptualization of IUM, it thus became possible to focus not only on the perceived threats at a given moment, but also on the possibilities in its four dimensions. Our conclusion therefore show up that the effect of the camcorder depends on the utility carried by messages, and there arose two patterns in selection mainly due to the interplay between utility and imagery:

a) imagery had a small impact with small effect size on news selection compared to utility of headlines which refers to individual's own capacity perception of preventing, handling a threat or utilizing an opportunity at a given moment or in the near future. One piece of research corroborates our finding, namely of Powell et al.' 
(2019) - who emphasize that headlines play a far greater role in news selection than images which have a minimal effect;

b) There is an exception from this when attached to low utility message, when the camcorder variable correlates with it, producing a very large effect size. This finding is consistent with two research findings: Gunter (2015) reports on a supposedly related phenomenon, albeit in connection with the news memory and the visual material rather than focusing on the selection of content. When measuring the news memory researchers encountered a similar phenomenon several times (see Katz et al., 1977; Booth, 1970). In the case of television news, if visual material was associated to less important news, it was remembered better than when visual material was associated to more important news. Although not based on IUM, and using important and less important headlines, Ambrus et al. (2011) faced a similar problem: how to explain the decrease of selection of important headlines with the camcorder, while the camcorder had increased the number of clicks on the less important ones with camcorder attached.

Due to the DCT framework, there arose another pattern that helped us to explain some of our findings. We were able to show up the possible importance of cognitive style in news selection with monosemic cues. Although the match between our students' visual cognitive style and the selection of news with camcorder did not correlate in the whole dataset, a tendency could be detected in " $p$ "-s a bit above the threshold $(<.06)$. At the same time, the statistical test proved that in some situations - in 2nd condition in our example - the visual scores can be accounted for by the selection of news with imagery. The verbal cognitive style did not play any role in selecting headlines without camcorder.

By including in analysis the verbal, the visual and the gender variables we could identify the responsabile group - participants with high scores on both verbal and visual scale - for the unexpected decrease or avoidance in selection of headlines with high utility.

The camcorder symbol, when considered as a peripheral cue - according to ELM - did not have the predicted effect within the experimental groups where the symbol was attached only to headlines with high utility. This subject will be discussed following the second experiment results.

\section{Second quasi-experiment}

\section{Overview}

The same language-speaking BA and MA students from another campus of the same university read online headlines. We made the same two transformations on the dataset as in the first quasi-experiment: mean centered the variables for the same reason as in the first experiment, and, becauseof systematic differences between the man and woman proportion in the sample, we weighted the gender variable. The proportion of gender was in inverse ratio to the first experiment $(N=241$; gender $N=69$ women, $N=172 \mathrm{men}$; average age $=24.2$, see Table 5$)$. 
Table 5

Descriptive statistics of gender

\begin{tabular}{|c|c|c|c|c|}
\hline & \multicolumn{2}{|c|}{ before weighting } & \multicolumn{2}{c|}{ after weighting } \\
\hline $\begin{array}{c}\text { man, } \\
\text { whole } \\
\text { dataset }(N)\end{array}$ & \multicolumn{2}{|c|}{172} & \multicolumn{2}{c|}{138} \\
\hline $\begin{array}{c}\text { woman, } \\
\text { whole } \\
\text { dataset }(N)\end{array}$ & \multicolumn{2}{|c|}{69} & \multicolumn{2}{c|}{} \\
\hline man $(N)$ & $\begin{array}{c}\text { priming } \\
\text { condition } \\
85\end{array}$ & $\begin{array}{c}\text { control } \\
\text { condition } \\
87\end{array}$ & $\begin{array}{c}\text { priming } \\
\text { condition } \\
85\end{array}$ & $\begin{array}{c}\text { control } \\
\text { condition } \\
87\end{array}$ \\
\hline woman $(N)$ & $\begin{array}{c}\text { priming } \\
\text { condition } \\
35\end{array}$ & $\begin{array}{c}\text { control } \\
\text { condition } \\
34\end{array}$ & $\begin{array}{c}\text { priming } \\
\text { condition } \\
70\end{array}$ & $\begin{array}{c}\text { control } \\
\text { condition } \\
68\end{array}$ \\
\hline
\end{tabular}

The quasi-experiment was based on the same theoretical framework as the first quasiexperiment, but differed in that we primed in the experimental group respondents' dominant cognitive style - verbal or visual (see Table 6) - with a visual cue: the camcorder symbol.

Table 6

IDQ scores in experimental groups

\begin{tabular}{|c|c|c|}
\hline & $\begin{array}{c}\text { Primed } \\
\text { experimental group: } \\
\text { low and high utility } \\
\text { headlines with } \\
\text { camcorder, mixed } \\
\text { condition }\end{array}$ & $\begin{array}{c}\text { Control group: } \\
\text { headlines without } \\
\text { camcorders and } \\
\text { priming }\end{array}$ \\
\hline $\begin{array}{c}\text { Average score on } \\
\text { verbal scale }\end{array}$ & 18.10 & 17.34 \\
\hline $\begin{array}{c}\text { Average score on } \\
\text { visual scale }\end{array}$ & 23.16 & 23 \\
\hline
\end{tabular}

One primed experimental group and one control group belonged to this experiment:

$1^{\text {st }}$ group: Respondents from experimental group $(N=120)$ were presented also 10 headlines. Camcorder symbols were attached to headlines as follows: one to a negative headline with high utility, one to a positive headline also with high utility, one symbol to a negative headline with low utility and, finally, to a positive one with low utility.

$2^{\text {nd }}$ group: Participants belonging to the control group $(N=122)$ read the same headlines as those in the experimental group, but they were not primed. Camcorder symbols were attached to headlines as follows: one to a negative headline with high utility, one to a positive headline also with high utility, one symbol to a negative headline with low utility and, finally, to a positive one with low utility.

\section{Hypothesis:}

Hypothesis 1 (H1). Due to the priming with the camcorder symbol in the first condition, respondents choose more headlines with the camcorder symbol than in the control condition. 
Hypothesis 2 (H2). Respondents who prefer verbal cognitive style will be affected by the priming to a minor extent; they will not select significantly more headlines with the camcorder than those from the control group.

Respondents from the experimental group could see, in the upper left corner of the screen, eight nature photos each containing the camcorder symbol (see picture 1 in Appendix). This is in contrast to participants in the control group who had no camcorder symbol in the pictures (see picture 2 in Appendix). Every photo suggested calm which was important not only for the purpose of the experiment, but was essential especially for the participants belonging to experimental condition, because calibrating the eye-tracker one by one for each person might cause discomfort. The priming took place before browsing the news, inside the camcorder symbol was inserted the acronym of the university news portal: Youth Index TV, which, in fact, was the name of the website used for our two experiments. We used supraliminal stimuli, that is, they can watch every picture with the camcorder symbols for 4 seconds, and they succeed each other in identical between-times.

\section{Results}

\section{Preliminary Analyses}

The Cronbach-alpha of the shortened form on X language of The Paivio-Harshman's Individual Differences Questionnaire (1983) was calculated for both scales. Verbal scale items yielded satisfactory .72 , and visual ones. 75 values.

The significant difference in selecting headlines with high vs. low utility could be detected by using Paired-Samples T Test on the whole dataset: respondents selected, on average, 1.73 headlines with high, and .97 with low utility, $t=10,59, d f=309, p=.001$.

The first hypothesis $(H 1)$ was not confirmed. Involving the Number of group variable and the number of headlines with camcorder, we ran an Independent T Test.Primedparticipants with dominant visual cognitive style in the experimental group selected less headlines with the camcorder $(M=1.32)$ than in the control group $(M=1.49)$, although this relationship was not significant $(t=-1.56, d f=296, p=.11)$.In order to find out the factors responsible for this decrease, we ran two hierarchical regressions for each condition to compare the correlations between them. In each casein Step 1 we entered the visual score, verbal score and dummy coded gender; in Step 2 the interaction terms of the first order: visual x verbal, visual x gender, verbal $\mathrm{x}$ gender; and in Step 3 we introduced the interaction terms of the second order: visual $\mathrm{x}$ verbal $\mathrm{x}$ gender).

Considering the three models of the primed experimental group, only the last model was significant compared to the models of the control group in which every model was significant.In the case primed experimental group only one significant partial correlation arose between the variable verbal $\mathrm{x}$ visual $\mathrm{x}$ gender and number of headlines with camcorder, a weak, negative relationship: $r=-.21, p=.00$. This result suggests the possible role of the interaction term in the decreased number of headlines with camcorder. The role of the verbal and visual variable, and of the gender can be shown up also in the control condition (see Table 7).

Table 7

The role of the gender and of the verbal and visual variable

\begin{tabular}{|c|c|c|}
\hline & $\begin{array}{c}\text { Standardized } \beta \\
\text { Primed experimental group }\end{array}$ & $\begin{array}{l}\text { Standardized } \beta \\
\text { Control group }\end{array}$ \\
\hline $\begin{array}{r}\text { Visual scores } \\
\text { Verbal scores } \\
\text { Women } \\
\end{array}$ & $\begin{array}{l}.01 \\
-.08 \\
-.05 \\
\end{array}$ & $\begin{array}{l}.16 \\
.09 \\
.10\end{array}$ \\
\hline
\end{tabular}




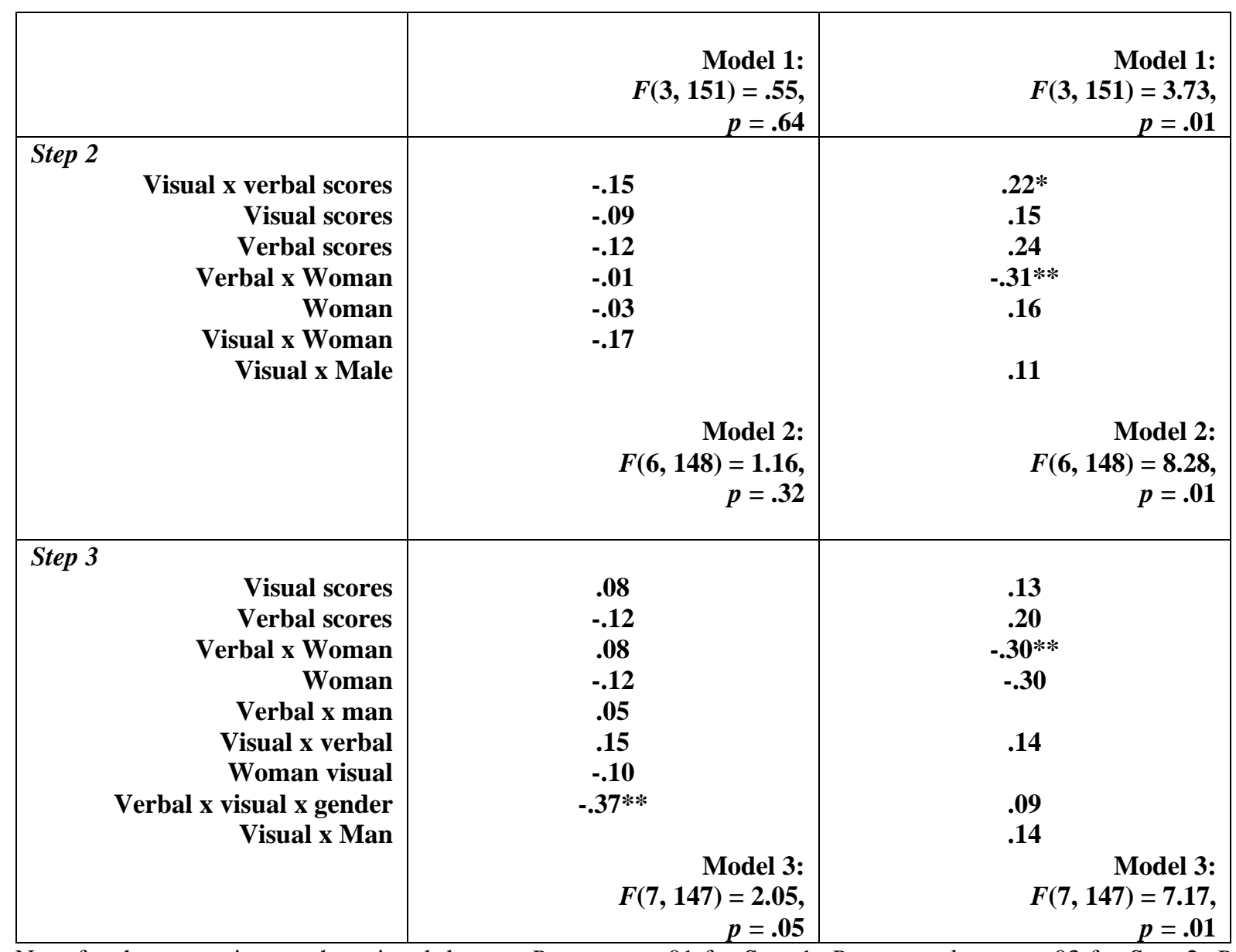

Note for the regression on the primed dataset. $R$ square $=.01$ for Step 1: $R$ square change $=.03$ for Step $2, R$ square $=.04$ for Step 3 .

Note for the regression on the second condition. $R$ square $=.06$ for Step 1: $R$ square change $=.18$ for Step $2, R$ square $=.00$ for Step 3

As in the case of the first experiment, we made use of PROCESS SPSS macro (Hayes, 2013) to analyze in more detail the role of verbal, visual and gender variables and their possible interactions in selection of headlines with camcorder. We made use of a pick-a-point procedure to reveal whether the groups differed, on average, from each other on the dependent variable, (determined by 5 values of the moderator variable). The selection of headlines with the camcorder symbol is dependent on the verbal scores beginning only from 50\% and up to $75 \%$ of it, followed by a decline at $90 \%$, but in this case reaching even the insignificancy (based on 5000 bootstrap, at $50 \% t=2.14, p=.03$, CI .0028-.0653, at $75 \% t=2.00, p=.04$, CI .0007.0888 , at $90 \% t=1.90, p=.05$, CI -.0017-.0098).

After dividing the database into experimental and control group, surprising results arose compared even to the first experiment. Then we worked out that the respondents with high scores on both visual and verbal scale avoid the camcorder symbol, now we noticed the fact that priming with the symbol did not increase the selection of headlines with camcorder symbols, in fact, they decreased it to a significant extent.

In the experimental condition primed with camcorder symbol respondents chose, on average, 1.32 headlines with the camcorder, as opposed to 1.49 in the control condition. Thus, the priming had an unanticipated effect on the selection: the value of $p$ increases far above the .05 threshold $(p=.87$, Unst. Beta $=-.01, d f .1,152)$. None of the other predictors involved in hierarchical regression had a significant effect on selection of the headlines in point. 
Even though in control condition priming was not applied, respondents' selection of headlines with the camcorder - with high and low utility - was determined by visual scores per se: $p=.005$, Unst. Beta $=.33, d f .1,145$.

We fine-tuned our analysis and checked how respondents' cognitive style, i.e. results obtained on both scales of the IDQ-test influenced their selection of headlines with the camcorder. As we aimed to keep our variables continuous, we created the independent variable involved in the following way: we sorted the ascending scores of the variable of the verbal scores, then, after calculating the mean, we marked both the value of one SD below the mean and of one SD above the mean. Thus, we created a new nominal variable in the next column with 3 levels, but taking into account the normal distribution of the scores in dividing it. We labeled them as follows: 1, those who had low scores on the verbal scale, 2, those who had average scores on the scale, and 3, those whose scores began from the value of M+1 SD. We proceeded in the same way with the variable of the visual scores, then merged in a single variable both visual and verbal scale scores: theVerbal_Visual_Group nominal variable. We ran an online regression in SPSS to test the effect of the Verbal_Visual_Group predictor on the headlines with the camcorder, using commands as follows: Graph $\rightarrow$ LegacyDialog $\rightarrow$ SimpleScatter $\rightarrow$ Define $\rightarrow$ Set Markers by.

Those who were high on both visual and verbal scales selected less and fewer headlines with the camcorder as their scores on visual scores increased. (Verbal H Visual H, 19 respondents, $12.3 \%$, the threshold of a strong correlation: $r_{=} .507$, see Figure 2). 
Figure 2. Avoidance attitude towards camcorder of high score respondents' on both verbal and visual scale. Analysis performed with SPSS Version 22.

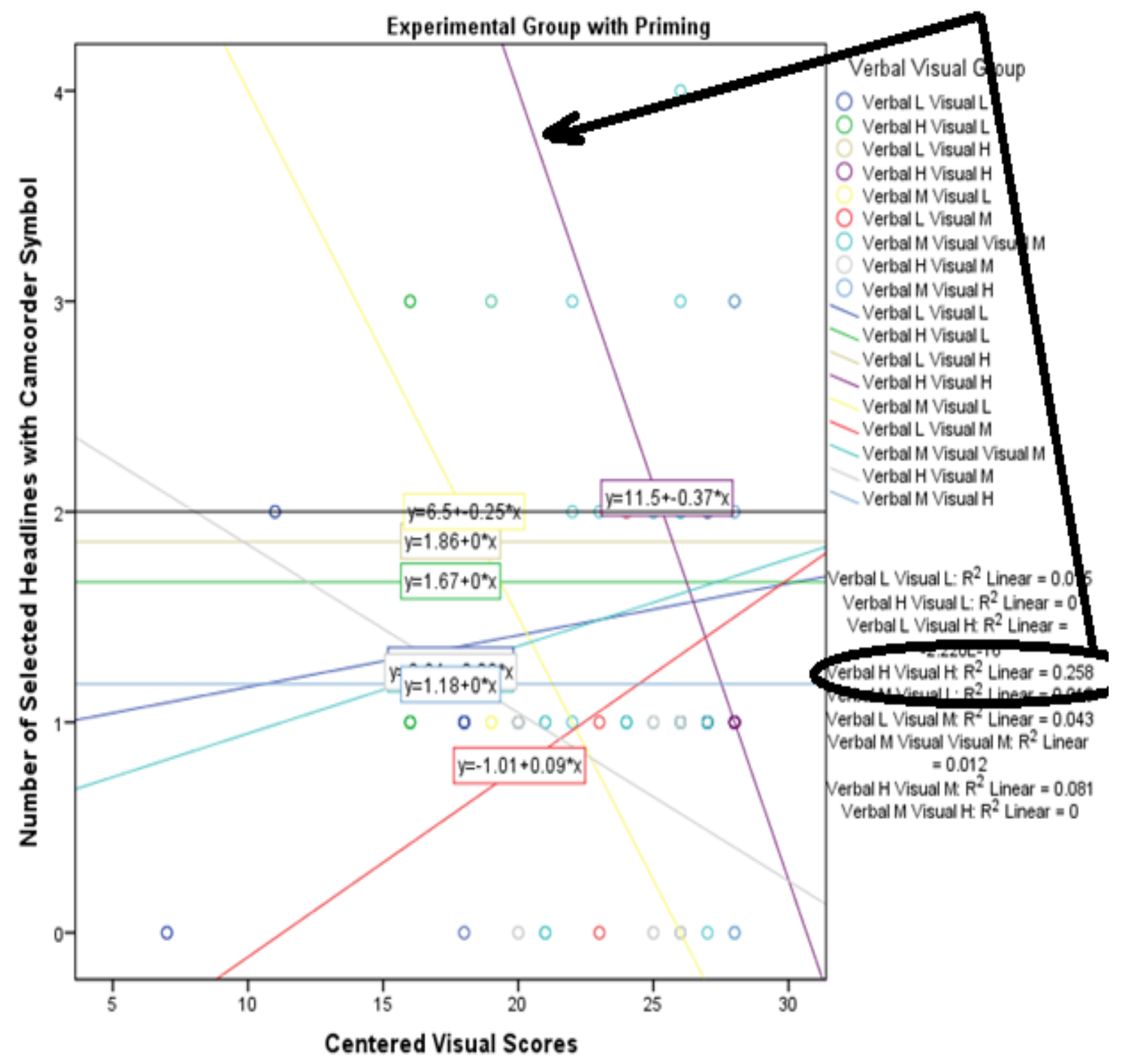

Cases weighted by Sex

However, these respondents with high scores on both scales selected more and more headlines with the camcorder as their visual scores increased: an almost high correlation $r=.47$ (Verbal $\mathrm{H}$ Visual $\mathrm{H}, 17$ participants, $11 \%$ ).

We ran a regression analysis in the same way as in the previous test, also on the headlines of high utility with camcorders for each condition. In this case an even stronger correlation than above $(\mathrm{r}=.56)$ could be detected: showing that priming in the experimental group decreased the number of headlines selected with camcorder among those who had high scores on both visual and verbal scales.

The second hypothesis (H2) was not supported. We ran a One-Way ANOVA with the Verbal Scale nominal variable - constructed taking into account the normal distribution of the scores in dividing it - as splitting criteria. Respondents with high scores on the verbal scale 
differed from each other in the number of selected headlines with camcorders. Those from the primed group selected significantly less such news $(M=1.04, S D=.73)$ compared to participants from control group $(M=2.09, S D=.87), p=.04$.

\section{Eye-tracking analysis}

We made use of Tobii eye tracker and analyzed data collected by it. We marked the camcorder symbols attached to headlines as Areas of Interest (AOI), as well as the bigger camcorder symbol, containing the Youth Index TV acronym that served as a priming tool. It should be noted that in marking the outline of the AOIs, the AOI-s attached to headlines were extended to the middle of the last word of the headlines, AOI-s applied to the acronym were twice the size of the camcorder itself.

Two measurements were used: while the so-called First fixation recorded the time of the first eye fixation on the symbol in our case, the Fixation count-include zero refers to the number of total fixations on the previously marked areas of interest.

Although respondents rarely fixated on one of the camcorders, the effect of symbols could unequivocally be shown with the help of statistical tests. The symbols in point had an effect when participants did not fixate on them, but they had been in the field of vision - even so two typical attitudes were detected by tracking fixations:

Respondents who had average scores on both visual and verbal scales were almost exclusively those who fixated on the camcorder symbol used in priming (Verbal M Visual M, $N=62$ ). Of the 155 participants, 26 fixated on the camcorder symbol, from which 16 were with average scores on the two scales. The remaining 10 fixations were split between the respondents of the other five groups with different results on the verbal-visual scale. Of the nine groups, members of two groups did not fixate on the symbol at all: those who were visual-oriented in the control group avoided the camcorder symbol in the experimental condition, i.e. those who had high scores on both verbal and visual scales (Verbal H Visual H), as well as those who had average scores on verbal and low on visual scale (Verbal M Visual L, 15 respondents, $9.7 \%$ ).

Similar to the previous group, respondents with average scores on verbal scale and low scores on visual one, yielded a surprising result: while a very strong correlation was detected in the control group $(r=.82)$ indicating the interest for the camcorder symbol, in the experimental group no such orientation could be detected $(r=.13)$. Most probably this change was due to the avoidance strategy against priming.

Finally, concerning the experimental group (high on both visual and verbal scales - who had not had any fixation on the symbol), we were curious how many headlines with the camcorder were selected by clicking following the priming. We may assume the avoiding strategy based partly on the fact that only 12 headlines of high utility with the camcorder were chosen by the 19 participants. It was even more salient that respondents in this condition selected only two low utility headlines with the camcorder.

\section{Discussion for experiment 2}

As in the high-choice media environment, every contact with media content - for example, starting television watching, listening to radio, browsing internet etc. - the very first moment of media use has an effect on the way that content will be processed and probably in many cases also on the next choice. Thus, the impact of the previously used media content on the following reactions, e.g. the effect of priming could also play an important role in news selection in an image saturated media context. It becomes even more important in the trial of finding out what happens when a media user first observes during media use an imagery, especially if the person in point has a visual cognitive style. We tried to answer these questions 
involving the same variables in the analyses as in the first experiment plus an eye-tracker - as far as we know, a first in the communication research field. We could conclude that imagery priming plays an important role in the selection of headlines with camcorder symbol.

The results of these two pieces of research are consistent with each other regarding from the perspective of IUM. Results could not even be explained by dominant cognitive style alone. Taking into consideration Paivio and Harshman's statement that the verbal and the visual systems are not independent systems, and that there is a constant interplay between them, we decide to involve the two scales in analysis at the same time. As far as we know, there has not been such a trial before this experiment in any field to explain a phenomenon linked to verbal and visual processing. We were able to explain by simultaneously involving both scales of the IDQ test (Paivio-Harshman, 1983) the above mentioned avoidance.

In both experiments the typical camcorder symbol avoiders were identified: those who had high scores on both verbal and visual scales. This avoidance attitude became even stronger among these respondents when priming was applied: it decreased the number of headlines selected with the camcorder symbol. Although detected only in the second experiment, another group may probably be linked to this kind of avoidance, namely those with medium scores on verbal scales and low on visual one.

It is probable that the camcorder symbol played different roles different conditions. When attached to low utility headlines in both experiments it worked as peripheral cue (ELM) for every participant - independently of cognitive style - suggesting an increased and acceptable importance for news. However, attaching it to high utility headlines possibly made the avoiders' group(s) more suspicious about the credibility of news, and they processed them on the central route, i.e. more motivated, more critically and more regularly (ELM). Priming made them in this sense even more suspicious, and could be linked to Brehm's theory of reactance (1966), to the fear from being manipulated. This way of processing is characteristic not only to the motivated but also to the persons with high cognitive ability. Consistent with this, the camcorder avoiders in our research scored high on both scores not only on verbal and visual scales, but they probably were also with high cognitive abilities. This assumption is probably supported by Silverman's (2002) findings: children with very high scores on IQ test got excellent results on visual-spatial tasks, and also on verbal-sequential tasks.

\section{Conclusions}

As stated in the introduction, few researchers have taken into consideration both textual and visual cues in explaining selective exposure to news. By testing three theories - the Elaboration Likelihood Model (ELM), the Dual Coding Theory (DCT) and the Information Utility Model (IUM) - and examining their variables side by side, the current two pieces of research have possibly made some advances in this regard.

Concerning the DCT theoretical framework, the role of cognitive style in selection of headlines may be present, even though the correlation between visual cognitive style and selection of headlines with camcorders shows only a tendency in our whole dataset - and in one condition, a statistical relationship. This result is only partially consistent with the earlier research findings from the literature that reveal an univocal relationship between preferred cognitive style in everyday actions (Childers et al., 1985) and selections of information and annotations during learning (Leutner \& Plass, 1998; Plass, Chun, Mayer, \& Leutner, 1998). Our finding is - first of all - probably due to specific utility dimensions of the news, which play a major role in the selection of headlines compared to monosemic visual cues. It seems very likely at the same time that this result arises from the interplay between the two factors in point, and could be extrapolated to situations that test selective exposure to news when utility 
dimensions from IUM are salient. Although previous research has revealed the major impact of imagery on textual cues - especially of photographs on news selection (for instance, Rosentiel, 2016) - one novelty of the present study was that it tested their effect using the theoretical framework of IUM, hopefully nuancing the former results from the literature. For example, consistent with Rosenstiel's (2016) finding, we revealed that imagery / camcorder attached to low utility headlines in our quasi-experiments worked probably as a peripheral cue (ELM), and very much increased their selection. However, we discovered that the camcorder symbol decreased the selection of high utility headlines - a phenomenon that could be partially explained by our specific usage of IDQ test.

One of the merits of our two pieces of research is that we took into consideration the constant interplay between the verbal and the visual systems (Paivio-Harshman, 1983), and involved them simultaneously in statistical analyses in both scales of the IDQ test. We have shown up not only a simple moderation between the verbal and visual variables, but we were able to involve the interplay in question, and thus detect an avoidance-pattern in the case of high utility headlines with camcorder in both pieces of research. The "avoiders" belonged to two groups of respondents: those with high scores on both verbal and visual scales, and those with average scores on verbal and low scores on visual scales. Respondents' avoidance attitudes, belonging to the second group were detected, however only in the second experiment and with the help of an eye-tracker. These attitudes remained unexplained by the current study. At the same time, using statistical analyses on eye-tracker data we were able to partially explain the possible cause of those respondents' avoidance attitudes who had high scores on the two scales in point. They were possibly more suspicious about the credibility of news, therefore processing them using the central route (ELM). Priming possibly made these avoiders even more suspicious and critical in the second quasi-experiment - their avoidance of high utility headlines with camcorder became more pronounced. The fear of being manipulated (Brehm, 1966) seems to be a plausible explanation for this phenomenon.

Albeit using other terminology - important news instead of headlines with high utility - a similar kind of avoidance of the important news (in our researches: headlines with high utility) can be found in the literature when they are associated with visual cues (see Katz et al., 1977; Booth, 1970; Ambrus et. al., 2011).

Both pieces of research have several limitations. The major limitation is that neither of the quasi-experiments were run in a real web environment: they were only very basic reproductions of the genuine website without functional links to the actual articles, and thus this environment could not really provide the results of an actual website. Therefore, the generalization of the results for the "real world" environment should be problematized; for example, participants could not access any of the video footage. Another limitation of these results is that students read news not from social media, but from a news site, which is not in line with this generation's news consumption habits. Finally, the gender variable was weighted in both pieces of research. Keeping in mind all these limitations, further research could be designed to deepen the understanding of the interplay between visual and textual cues.

\section{References}

Ambrus, Z., Kósa, I., \& Zsigmond, Cs. (2011). Influenţa simbolului video asupra preferinţei ştirilor online. In: Iluţ P. (coord.), ,Studii de sociopsihologie”, Presa Universitară Clujeană.

Amit, E., Gottlieb, S., \& Greene, J. D. (2014). Visual versus verbal thinking and dual-process moral cognition. In J. W. Sherman, B. Gawronski, \& Y. Trope (Eds.), Dual-process theories of the social mind (p. 340-354). The Guilford Press. 
Atkin, C. K. (1973). Instrumental utilities and information seeking. In P. Clarke (Ed.), New models for communication research (205-242). Beverly Hills, CA: Sage.

Blazhenkova, O., \& Kozhevnikov, M. (2009). The new object-spatial-verbal cognitive style model: Theory and measurement. Applied Cognitive Psychology: The Official Journal of the Society for Applied Research in Memory and Cognition, 23(5), 638-663. CrossRef

Casas, A., \& Williams, N. W. (2019). Images that Matter: Online Protests and the Mobilizing Role of Pictures. Political Research Quarterly, 72(2), 360-375 CrossRef

Childers, T. L., Houston, M. J., \& Heckler, S. E. (1985). Measurement of individual differences in visual versus verbal information processing. Journal of Consumer Research, 12(2), 125-134.

Clark, J. M., \& Paivio, A. (1991). Dual coding theory and education. Educational psychology review, 3(3), 149-210.

Donohew, L., Palmgren, P., \& Duncan, J. (1980). An activation model of information exposure. Communication Monographs, 47(4), 295.

Fahmy, S., Bock, M. A., \& Wanta, W. (2014). Visual communication theory and research: Amass communication perspective. NewYork, NY: PalgraveMacmillan.

Graber, D. (1988). Processing the news. How people tame the information tide (2 ${ }^{\text {nd }}$ ed.). White Plains, NY: Longman.

Hayes, A. F. (2013). Introduction to mediation, moderation, and conditional process analysis: A regression-based approach. New York, NY: The Guilford Press.

Johnson, B. K., \& Knobloch-Westerwick, S. (2017). Steer Clear or Get Ready: How Coping Styles Moderate the Effect of Informational Utility, Journal of Broadcasting \& Electronic Media, 61:2, 332-350. CrossRef

Hastall, M. R. (2009). Informational utility as determinant of media choices. In T. Hartmann (Hrsg.), Media Choice: A theoretical and empirical overview (pp. 149-166). New York: Routledge.

Höffler, T. N., Koć-Januchta, M., \& Leutner, D. (2017). More Evidence for Three Types of Cognitive Style: Validating the Object-Spatial Imagery and Verbal Questionnaire Using Eye Tracking when Learning with Texts and Pictures. Applied cognitive psychology, 31 (1), 109-115. CrossRef

Jawed, S., Amin, H. U., Malik, A. S., \& Faye, I. (2018, August). Differentiating Between Visual and Non-Visual Learners Using EEG Power Spectrum Entropy. 2018 International Conference on Intelligent and Advanced System (ICIAS), Kuala Lumpur, 2018, pp. 1-4. CrossRef

Kim, Y. M. (2008). Where is my issue? The influence of news coverage and personal issue importance on subsequent information selection on the Web. Journal of Broadcasting \& Electronic Media, 52 (4), 600-621. CrossRef

Knobloch, S., Hastall, M., Zillmann, D., \& Callison, C. (2003). Imagery effects on the selective reading of Internet newsmagazines: A cross-cultural examination. Communication Research, 30 (1), 3-29.

Knobloch, S., DillmanCarpentier, F., \& Zillmann, D. (2003). Effects of salience dimensions of informational utility on selective exposure to online news. Journalism \& Mass Communication Quarterly, 80 (1), 91-108. CrossRef

Knobloch, S., Patzig, G., \&Hastall, M. R. (2002). "Informational Utility" - Einfluss von Nützlichkeit auf selevktiveZuwendungzunegatieven und positieven OnlineNachrichten [Informational utility: Impact of utility on selective exposure to negative and positive online news]. Medien- \& Kommunikationswissenschaft, 50(3), 359-357. 
Knobloch, S., Zillmann, D., Gibson, R., \&Karrh, J. A. (2002). Effects of salient news items on information acquisition and issue perception. Zeitschrift fürMedienpsychologie, 14(1), 14-22.

Knobloch-Westerwick, S. (2008). Informational utility. In W. Donsbach (Ed.), The international encyclopedia of communication (pp. 2273-2276). Malden, MA: Blackwell Publishing.

Knobloch-Westerwick, S. (2015). Choice and preference in media use. Advances in selective exposure theory and research. New York and London: Routledge,Taylor and Francis Group.

Knobloch-Westerwick, S., Hastall, M. R., Grimmer, D., \& Brück, J. (2005). Der Einfluss der Selbstwirksamkeit auf die selective Zuwendung zu Nachrichten [Informational utility: The influence of efficacy on recipients' news selection]. Publizistik, 50(4), 462-474.

Koć-Januchta, M. M., Höffler, T. N., Eckhardt, M., \& Leutner, D. (2019). Does modality play a role? Visual-verbal cognitive style and multimedia learning. Journal of Computer Assisted Learning 35(6) 747-757. CrossRef

Koć-Januchta, M., Höffler, T., Thoma, G. B., Prechtl, H., \& Leutner, D. (2017). Visualizers versus verbalizers: Effects of cognitive style on learning with texts and pictures-An eye-tracking study. Computers in Human Behavior, 68, 170-179. CrossRef

Kraemer, D. J., Hamilton, R., Messing, S. B., DeSantis, J. H., \& Thompson-Schill, S. L. (2014). Cognitive style, cortical stimulation, and the conversion hypothesis. Frontiers in human neuroscience, 8,15 . CrossRef

Krohne, H. W. (Ed.). (1993). Attention and Avoidance: Strategies in Coping with Aversiveness. Göttingen, Germany: Hogrefe\& Huber.

Lee, J. H. (2008). Effects of news deviance and personal involvement on audience story selection: A web-tracking analysis. Journalism \& Mass Communication Quarterly, 85(1), 41-60.

Leutner, D., \& Plass, J. L. (1998). Measuring learning styles with questionnaires versus direct observation of preferential choice behavior in authentic learning situations: The Visualizer/Verbalizer Behavior Observation Scale (VV-BOS). Computers in Human Behavior, 14(4), 543-557.

Nisbett, R. E., \& Ross, L. (1980). Human inference: Strategies and shortcomings of social judgment. New York, NY: Prentice Hall.

Outing, S., \& Ruel, L. (2004). What we saw through their eyes [online document]. Retreived from www.poynter.org/extra/eyetrack2004/index.htm

Paivio, A., \& Harshman, R. (1983). Factor analysis of a questionnaire on imagery and verbal habits and skills. Canadian Journal of Psychology/Revue canadienne de psychologie, 37(4), 461-483.

Petty, Richard E., \& Joseph R. Priester (1994): Mass media attitude change: Implications of the elaboration likelihood model of persuasion. In Bryant, J., \& Zillmann, D. (Eds.), Media effects: Advances in Theory and Research (91-122). Hillsdale, NJ: Erlbaum.

Plass, J. L., Chun, D. M., Mayer, R. E., \& Leutner, D. (1998). Supporting visual and verbal learning preferences ina second language multimedia learning environment. Journal of Educational Psychology, 90, 25-36.

Powell, T. E., van der Meer, T. G. L. A., \& Brenes Peralta, C. (2019). Picture power? The contribution of news visuals to politically motivated selective exposure. Media and Communication, 7(3), 12-31. CrossRef

Pratto, F., \& John, O. P. (1991). Automatic vigilance: The attention-grabbing power of negative social information. Journal of Personality and Social Psychology, 61(3), 380-391. CrossRef 
Révész, Gy., Bernáth, L., \& Séra, L. (1995). A Paivio-féle" Individual Differences Questionnaire" magyar változata. Magyar Pszichológiai Szemle, 35, 327-343.

Rosenstiel, T. (2016). Solving journalism's hidden problem: Terrible analytics. Center for Effective Public Management, February, 1-18.

Sargent, S. L. (2007). Image effects on selective exposure to computer-mediated news stories. Computers in Human Behavior, 23, 705-726. CrossRef

Sears, D. O., \& Freedman, J. L. (1967). Selective exposure to information: A critical review. Public Opinion Quarterly, 31(2), 194-213. CrossRef

Sundar, S. S., \& Kim, J. (2005). Interactivity and persuasion: Influencing attitudes with information and involvment, Journal of Interactive Advertising, 5, 2. Accessed: 10 March 2014. http://jiad.org/article59.html

Wentura, D., Rothermund, K., \& Bak, P. (2000). Automatic vigilance: The attention-grabbing power of approach- and avoidance-related social information. Journal of Personality and Social Psychology, 78(6), 1024-1037. CrossRef

Zillmann, D. (1999). Exemplification theory: Judging the whole by some of its parts. Media Psychology, 1(1), 69-94. CrossRef

Zillmann, D., Gibson, R., \& Sargent, S. L. (1999). Effects of photographs in news-magazine reports on issue perception. Media Psychology, 1 (3), 207-228. CrossRef

Zillmann, D., Knobloch, S., \& Yu, H. S. (2001). Effects of photographs on the selective reading of news reports. Media Psychology, 3(4), 301-324. $\underline{\text { CrossRef }}$

\section{Appendix}

\section{Picture 1.}

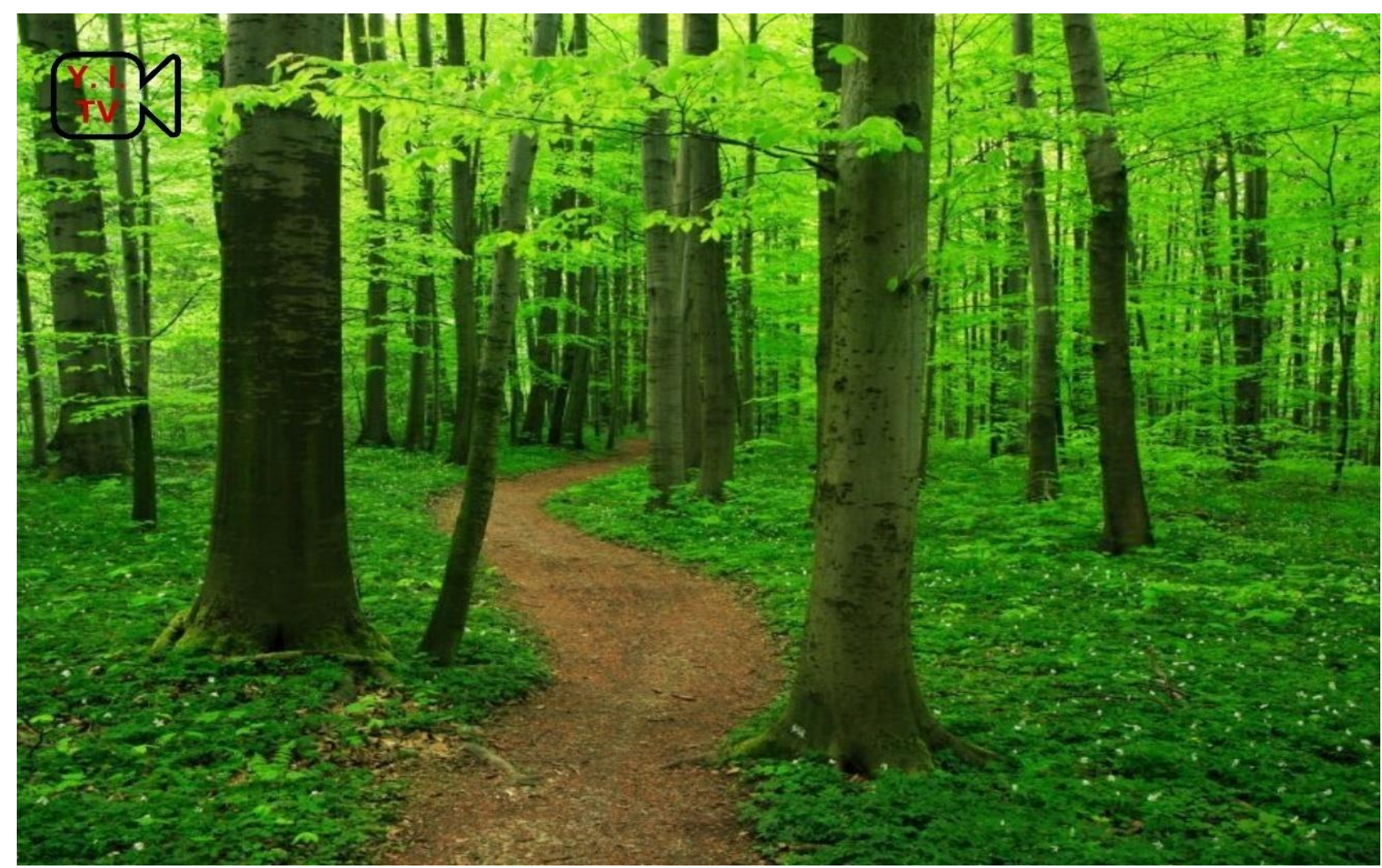


Picture 2.

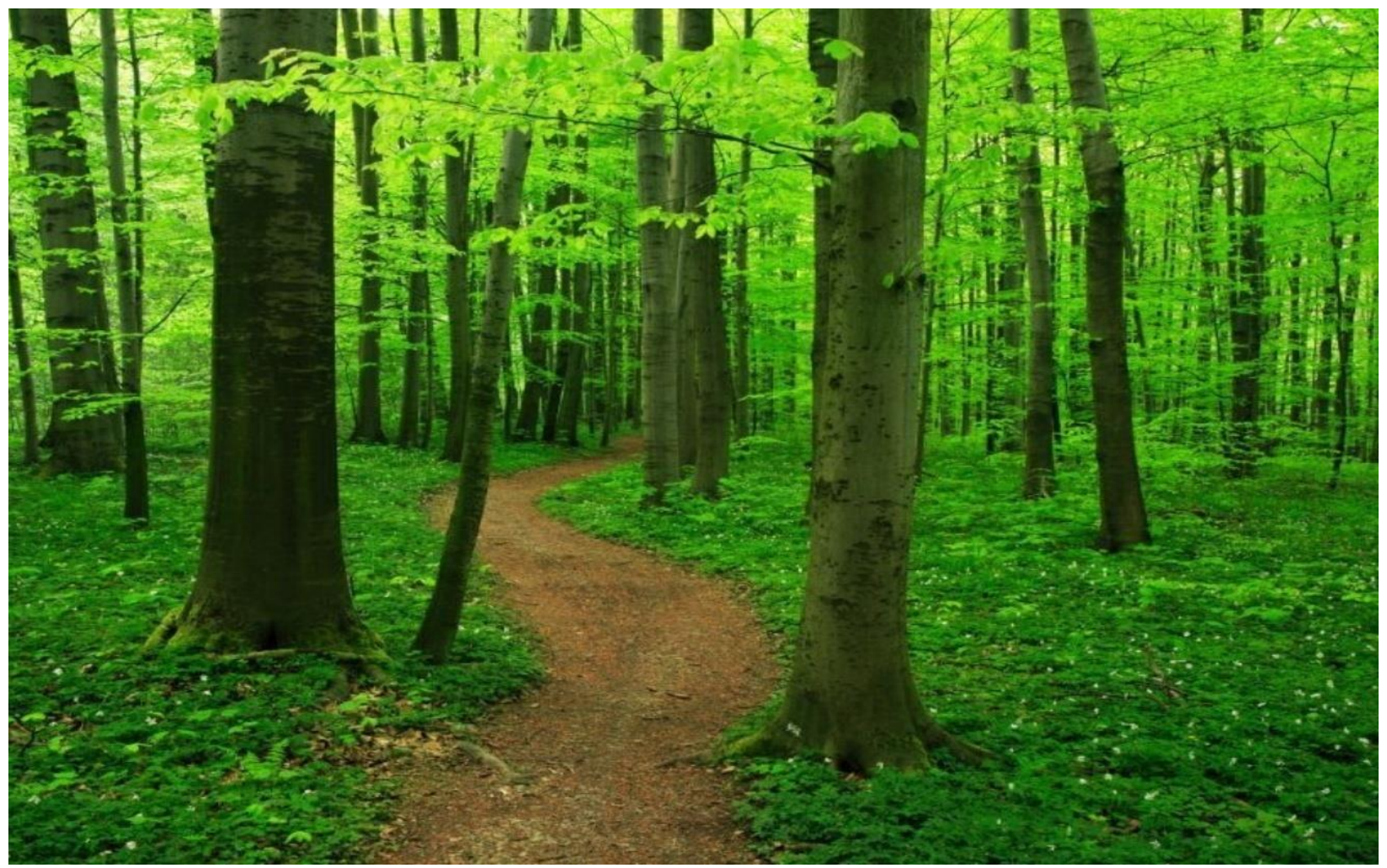

